\title{
OPEN High fat diet-induced obesity prolongs critical stages of the spermatogenic cycle in a $\mathrm{LdIr}^{-I-}$. Leiden mouse model
}

\author{
D. Komninos ${ }^{1,6}$, L. Ramos ${ }^{1,6}$, G. W. van der Heijden ${ }^{1}$, M. C. Morrison ${ }^{20,3}$, R. Kleemann²,
} A. E. van Herwaarden ${ }^{4}$, A. J. Kiliaan ${ }^{5,6 \unrhd}$ \& I. A. C. Arnoldussen ${ }^{5,6}$

Obesity can disturb spermatogenesis and subsequently affect male fertility and reproduction. In our study, we aim to elucidate at which cellular level of adult spermatogenesis the detrimental effects of obesity manifest. We induced high fat diet (HFD) obesity in low-density lipoprotein receptor knock-out Leiden (Ldlr ${ }^{-1}$. Leiden) mice, and studied the morphological structure of the testes and histologically examined the proportion of Sertoli cells, spermatocytes and spermatids in the seminiferous tubules. We examined sperm DNA damage and chromatin condensation and measured plasma levels of leptin, testosterone, cholesterol and triglycerides. HFD-induced obesity caused high plasma leptin and abnormal testosterone levels and induced an aberrant intra-tubular organisation (ITO) which is associated with an altered spermatids/spermatocytes ratio (2:1 instead of 3:1). Mice fed a HFD had a higher level of tubules in stages VII + VIII in the spermatogenic cycle. The stages VII + VII indicate crucial processes in spermatogenic development like initiation of meiosis, initiation of spermatid elongation, and release of fully matured spermatids. In conclusion, HFD-induced obese LdIr $^{-1-}$. Leiden mice develop an aberrant ITO and alterations in the spermatogenic cycle in crucial stages (stages VII and VII). Thereby, our findings stress the importance of lifestyle guidelines in infertility treatments.

The impact of obesity on female fertility has been described thoroughly, and obesity has been associated with menstrual disorders, anovulation, polycystic ovarian syndrome, increased risk of miscarriage and reduced conception rate ${ }^{1-3}$. In slight contrast, the research field addressing the impact of obesity in male fertility is underexplored, whereas male fertility is also compromised in obese men ${ }^{4-6}$. Specifically male obesity is associated with decreased sperm quantity and quality, consequently resulting in decreased pregnancy rates and increased pregnancy loss in assisted reproduction ${ }^{4,6,7}$. Obesity can affect spermatogenesis via several mechanisms and processes, among others via hormonal changes. For instance leptin, a hormone produced by adipose tissue, inhibits the androgen production of Leydig cells in the testis ${ }^{8-10}$. Thereby, long-term exposure to high leptin levels can eventually lead to a decreased testosterone production ${ }^{8,9}$. Secondly, oestrogen levels are elevated in men with obesity, which is associated with a reduced testis size and low sperm quantity and quality ${ }^{8,11}$. Specifically, aromatase in adipose tissue converts testosterone into oestradiol, which results in elevated oestrogen levels in obese $\operatorname{men}^{4,8,12,13}$. Moreover, oestrogen inhibits the testosterone production via the hypothalamic-pituitary-gonadal (HPG) axis ${ }^{9}$. Therewith, excessive amounts of adipose tissue can decrease testosterone concentrations and thereby spermatogenesis through increase of leptin and oestrogen. Thirdly, in men with obesity the testicular temperature may be increased due to excessive adipose tissue stored in the testes ${ }^{4,13-16}$. This may result in increased apoptosis and DNA damage in developing sperm cells due to excessive levels of oxidative stress and/or an abnormal chromatin condensation ${ }^{17-21}$. In line with this hypothesis, some studies have indeed shown that obesity leads

${ }^{1}$ Department of Obstetrics and Gynaecology, Radboud University Medical Center, Geert Grooteplein Zuid 10, 6525 GA Nijmegen, The Netherlands. ${ }^{2}$ Department of Metabolic Health Research, Netherlands Organisation for Applied Scientific Research (TNO), Zernikedreef 9, 2333 CK Leiden, The Netherlands. ${ }^{3}$ Department of Human and Animal Physiology, Wageningen University, De Elst 1, 6708 WD Wageningen, The Netherlands. "Department of Laboratory Medicine, Radboud University Medical Center, Geert Grooteplein Zuid 10, 6525 GA Nijmegen, The Netherlands. ${ }^{5}$ Department of Medical Imaging, Anatomy, Donders Institute for Brain, Cognition and Behaviour, Preclinical Imaging Center PRIME, Radboud University Medical Center, Geert Grooteplein Noord 21, 6525 EZ Nijmegen, The Netherlands. ${ }^{6}$ These authors contributed equally: D. Komninos, L. Ramos, A. J. Kiliaan, and I. A. C. Arnoldussen. ${ }^{\square}$ email: Amanda.Kiliaan@Radboudumc.nl 


\begin{tabular}{|l|l|l|}
\hline Parameter (36 weeks of age) & Control & HFD \\
\hline Body weight $(\mathrm{g})$ & $37.82 \pm 1.23$ & $49.56 \pm 0.90^{* * *}$ \\
\hline Body fat $(\%)$ & $8.78 \pm 0.48$ & $11.56 \pm 0.58^{* * *}$ \\
\hline Plasma cholesterol $(\mathrm{mM})$ & $8.65 \pm 0.38$ & $28.17 \pm 2.41^{* * *}$ \\
\hline Plasma triglycerides $(\mathrm{mM})$ & $1.20 \pm 0.06$ & $2.87 \pm 0.44^{* * *}$ \\
\hline Plasma leptin $(\mathrm{ng} / \mathrm{mL})$ & $21.46 \pm 3.04$ & $50.73 \pm 2.60^{* * *}$ \\
\hline Plasma testosterone $(\mathrm{nnmol} / \mathrm{L})($ median $(\mathrm{IQR}))$ & $5.86(7.41)$ & $5.23(73.69)$ \\
\hline
\end{tabular}

Table 1. Metabolic parameters. ${ }^{*} p<0.05,{ }^{* * *} p<0.001^{35}$. IQR Interquartile range.

to higher proportion of sperm with DNA fragmentation ${ }^{22-24}$. However, research examining male fertility in obesity is rather limited compared to studies in women and results are rather ambiguous. In more detail, previous studies have demonstrated the adverse effects of obesity on one or more semen parameters, like ejaculate volume, sperm concentration, sperm motility and morphology $y^{4,722-28}$, whereas some other authors reported no significant alterations in spermatogenesis of individuals with obesity ${ }^{14,29-32}$. Testicular biopsies are necessary to examine cellular alterations in spermatogenesis changes in men, which is a limitation in this type of research. We examined the effect of high fat diet (HFD)-induced obesity in low-density lipoprotein receptor knock-out Leiden (LDLr ${ }^{-/-}$.Leiden) mice. In particular, we aimed to clarify the HFD-induced cellular alterations in adult spermatogenesis, and assessed at which level of spermatogenesis the detrimental effects of high fat diet (HFD)induced obesity manifest ${ }^{33,34}$. This study may provide insight into the biological understanding of decreased male fertility in obesity which stresses the importance of lifestyle guidelines in male infertility treatment.

\section{Results}

HFD-fed mice had a significant higher body weight, body fat and plasma leptin levels. After 24-weeks of HFD-feeding, both body weight and body fat were significantly increased in HFD-fed Ldlr ${ }^{-/}$. Leiden mice compared to mice on control diet. In more detail, the HFD-fed mice were $31.04 \%$ heavier and had $31.66 \%$ more body fat than mice in the control group (Table 1). Accordingly, plasma leptin levels of HFD fed mice were significantly higher (2.4 times) than mice on control diet (Table 1 ). HFD fed mice showed higher mean level of total testosterone compared to control group and overall testosterone levels varied a lot between the mice, independent of dietary group. No significant difference between dietary groups in testosterone levels (Table 1).

HFD fed mice showed aberrant intra-tubular organisation. We performed histological analyses of the testes to evaluate whether the HFD-induced obesity affected the organisation of the seminiferous tubules. No significant differences were found in the testis weight and volume between the two dietary groups (Supplementary Table S1). Nor did we find significant differences in the relative and absolute number of seminiferous tubules in the testis and in the thickness of the seminiferous epithelium (Supplementary Table S1). Nevertheless, the analysis of the different types of atypical tubules, a difference in aberrant intra-tubular organisation (ITO) was found. In more detail, the percentage of aberrant ITO tubules was 2.8 times higher in the testes of the HFD fed mice compared to mice fed the reference diet $(\mathrm{p}<0.001$; Fig. $1 \mathrm{~A}-\mathrm{C})$. In more detail, mice in the reference group showed an average of $16 \%$ aberrant ITO tubules, whereas the HFD-fed mice had an average of $44 \%$. Moreover, the percentage of tubules with aberrant ITO showed a strong positive correlation with the body weights of the mice $(\mathrm{r}=0.69, \mathrm{p}<0.001, \mathrm{n}=27)$ and with the plasma leptin levels $(\mathrm{r}=0.71, \mathrm{p}<0.001, \mathrm{n}=27)$. Interestingly, aberrant ITO tubules were negatively correlated with the spermatids/spermatocytes ratio $(r=-0.48, p=0.04$, $\mathrm{n}=19$ ). In addition, in normal developed tubules the spermatids/spermatocytes ratio is $3: 1$, while in tubules with an aberrant germ-cell organisation the ratio is 2:1. All in all, these findings indicated that HFD-induced obesity significantly increased the level of aberrant ITO of the seminiferous tubules and significantly lowered the spermatids/spermatocytes ratio.

Number of Sertoli cells is strongly associated with number of developed spermatids. The number of Sertoli cells, primary spermatocytes and elongating spermatids was not significantly different between dietary groups (Fig. 2). This was also the case for the ratio of elongating spermatids over spermatocytes. Nevertheless, a strong positive correlation was found between the number of Sertoli cells and spermatogonia $(\mathrm{r}=0.74, \mathrm{p}<0.01, \mathrm{n}=19)$, and secondly, between Sertoli cells and the ratio of spermatids/spermatocytes $(\mathrm{r}=0.61$, $\mathrm{p}<0.01, \mathrm{n}=19$ ). Thus, we observed that the total number of Sertoli cells was strongly associated with the number of developed spermatids, which confirms the supportive function of Sertoli cells during spermatogenesis.

HFD-feeding delayed the spermatogenic cycle in stage VII + VIII. To determine whether the HFDinduced obesity affected a specific developmental stage of spermatogenesis, we examined the developmental stages of 52 seminiferous tubules per testis per mouse. We found that the spermatogenic cycle stage per seminiferous tubule (stage I-XII) and the distribution of the seminiferous stages was significantly different between dietary groups. Specifically, HFD-fed mice had significantly more seminiferous tubules in stage VII (14.73\%) than mice in the control group $(10.21 \%, p=0.01$, Fig. $3 \mathrm{~A})$. As elongated spermatozoa are released during stage VIII and the difference between stage VIII and IX can be accurately determined based on the presence of spermatozoa. Thereby, we combined stages VII and VIII and stages IX and X to examine, whether the release of 

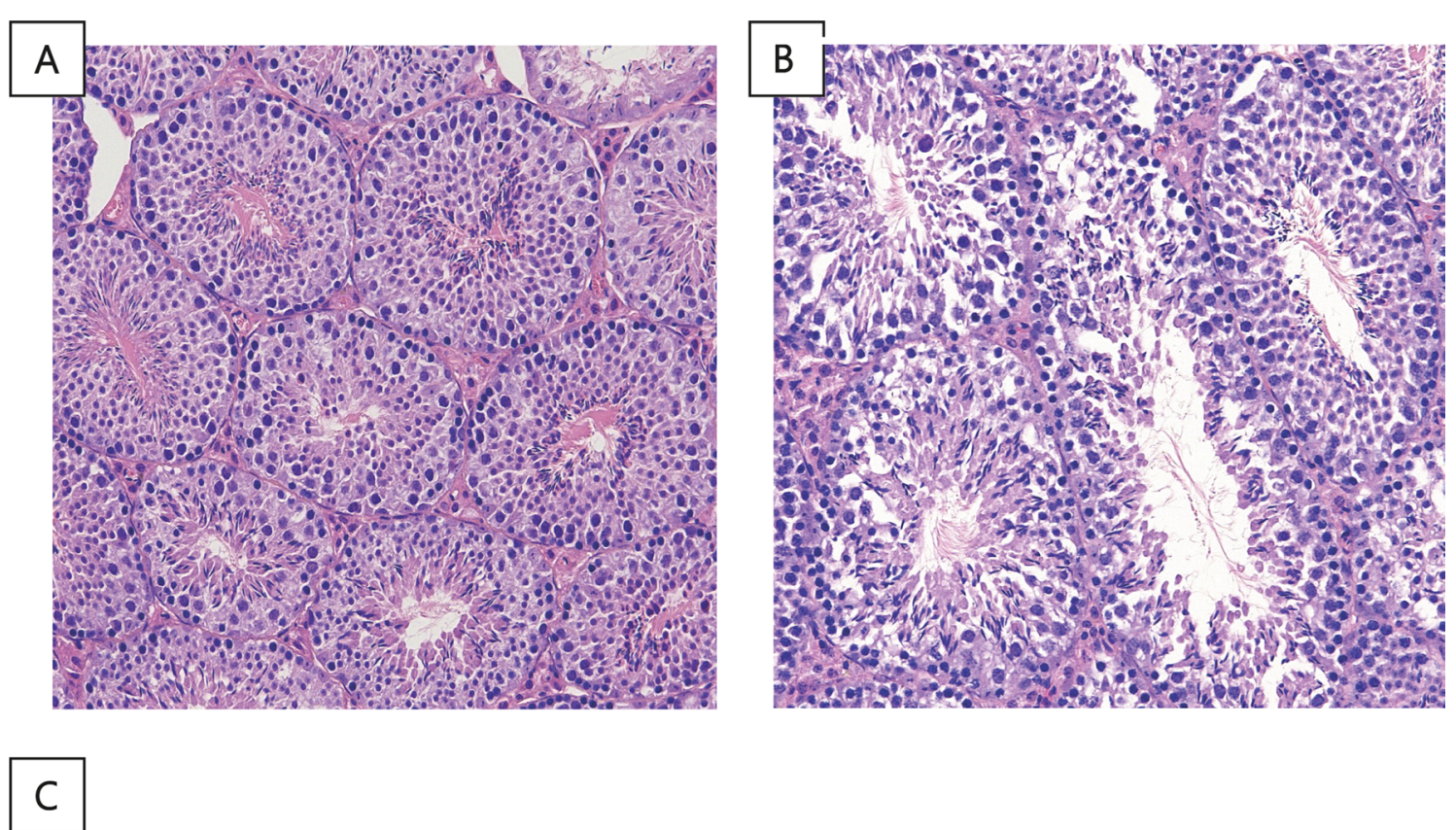

Aberrant intra-tubular organisation

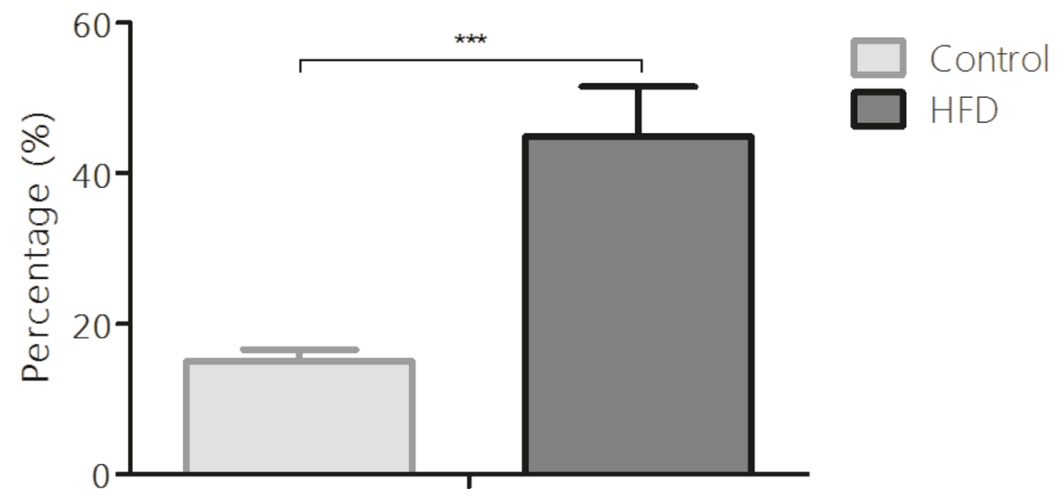

Figure 1. Analyses and representative images of testis morphology. (A) Normal tubules. (B) Tubules with an aberrant intra-tubular organisation. (C) Quantification of the seminiferous tubules (in total 52 tubules per mouse) with an aberrant intra-tubular organisation. Original magnification $\times 200$. Control $n=13$. HFD $n=14$. $* * * \mathrm{p}<0.001$.

spermatozoa differed between dietary groups (Fig. 3B). We found that HFD fed mice had significantly more tubules in stages VII + VIII $(32.6 \%, \mathrm{p}=0.041)$ and consequently less tubules continued to stages IX $+\mathrm{X}(12.6 \%$, $\mathrm{p}=0.014)$, when compared to mice fed the reference diet $(26.0 \%$, stage VII + VIII, and $18.5 \%$ in stage IX $+\mathrm{X})$. Moreover, the combined stages VII + VIII also positively correlated with body weight $(\mathrm{r}=0.60, \mathrm{p}<0.01, \mathrm{n}=19)$ and plasma leptin levels $(\mathrm{r}=0.59, \mathrm{p}<0.01, \mathrm{n}=19)$. Additionally, the combined stages IX $+\mathrm{X}$ also showed a mild negative correlation with the percentage aberrant ITO tubules $(r=-0.52, p<0.01, n=19)$. Altogether, these findings showed that HFD-induced obesity affected the spermatogenic cycle in stage VII + VIII.

HFD did not affect DNA damage in the testis and chromatin condensation in spermatozoa. No significant differences in TUNEL + levels were observed between dietary groups for either the total number or numbers per germ cell type $(\mathrm{p}=0.44, \mathrm{~F}(1,28)=0.61$, Fig. $4 \mathrm{~A}-\mathrm{C})$, nor for the number of CMA $3+$ spermatozoa $(\mathrm{p}=0.22, \mathrm{~F}(1,13)=1.67$, Fig. $4 \mathrm{D}, \mathrm{E})$.

\section{Discussion}

In this study, we investigated the impact of HFD-induced obesity on spermatogenesis in $\mathrm{Ldlr}^{-/-}$. Leiden mice. After 24 weeks of HFD feeding, these mice developed increased body weight, excessive storage of white adipose tissue, hypercholesteremia, hyperlipidaemia and high plasma leptin levels. These findings are all in line with previous research in this mouse model ${ }^{35-37}$. Notably, we found that HFD-induced obesity induced the significant higher formation of seminiferous tubules with aberrant intra-tubular organisation, which was associated with an altered spermatids/spermatocytes ratio (2:1 instead of 3:1). In addition, HFD feeding induced a higher level of tubules in developmental stage VII and VIII, which could indicate a prolonged spermiation in stage VII and VIII. 


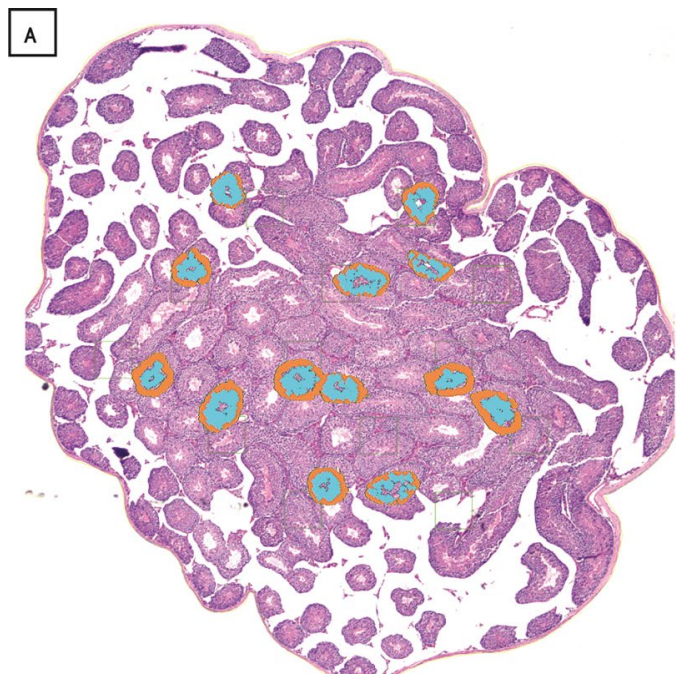

Figure 2. Analysis of sperm cells and Sertoli cells. (A) Overview of the analysis in one section, per testis four randomly selected sections were counted. Magnification $\times 25$. (B) Quantification of Sertoli cells, spermatocytes, and spermatids per testis. Control $\mathrm{n}=10$. HFD $\mathrm{n}=10$.

A

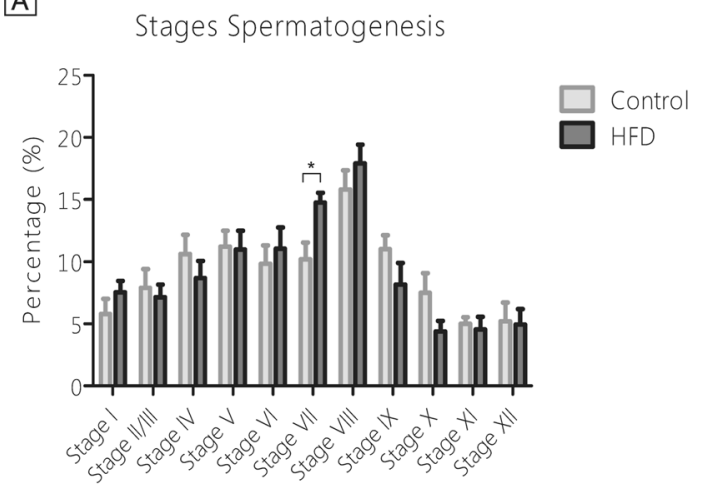

B

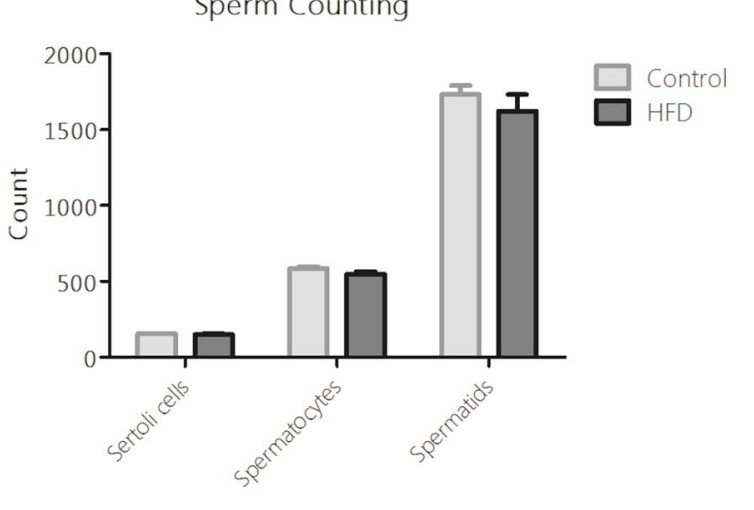

Figure 3. Stages of spermatogenesis in seminiferous tubules. (A) Analysis of the seminiferous stages, displayed as percentage of the total number of seminiferous tubules analysed. (B) Analysis of the stages VII \& VIII and IX $\& \mathrm{X}$, displayed as percentage of the total number of seminiferous tubules analysed. Control $\mathrm{n}=10$. HFD $\mathrm{n}=10$. ${ }^{*} \mathrm{p}<0.05$.

We found no significant difference in plasma testosterone levels in HFD-induced obese $\mathrm{Ldlr}^{-/-}$.Leiden mice, which is in contrast with other studies ${ }^{38}$. Still, some exceptionally high testosterone levels were found in specifically the HFD-fed mice, which were not related to other findings for instance aberrant intra-tubular organisation. It could be hypothesized that constant high levels of leptin starting at young age could lead to a testicular leptin resistance and thereby alter testosterone production. This has been observed in a previous study on the effects of leptin in rats ${ }^{39}$. These findings might be explained by a change in lipid composition due to HFD-feeding, particularly by an increase in mono-unsaturated fatty acids (MUFA) ${ }^{40}$. A previous study examining lipid composition in the testis and testosterone production has demonstrated that MUFA's, contradictory to poly unsaturated fatty acids (PUFA's), increase testosterone production ${ }^{41}$. More specifically, it has been shown that MUFA's increase free testosterone levels, possibly by decreasing the binding to Sex hormone-binding globulin (SHBG $)^{41,42}$. Thus, the testosterone production might be affected by testicular leptin resistance and/or the increase of MUFA's. Future research in this mouse model should clarify the underlying processes and biological mechanisms involved.

To note, the testes of the HFD-induced obese mice showed significantly more aberrant ITO than the testes of the control group. Hyperleptinemia has been proven to directly impair the testicular structure ${ }^{43}$. The impaired testicular structure could be the result of an impaired blood-testis-barrier (BTB), which could result in decreased Sertoli cell functioning and sperm cell development ${ }^{10,44}$. Hyperleptinemia could disrupt cell adhesion between spermatogenic cells and Sertoli cells, which could be the origin of the observed aberrant ITO ${ }^{45,46}$. Moreover, hyperleptinemia may affect functioning of Sertoli cells via alterations in the HPG axis, and via lactate and acetate production ${ }^{44}$ causing impaired germ cell nourishing ${ }^{8,47,48}$. A diet abundant in unsaturated fatty acids can lower membrane fluidity, which can lead to compromised function of the cellular membrane ${ }^{49,50}$. The increased membrane rigidity could have contributed to the observed atypical morphology of the seminiferous tubules in 

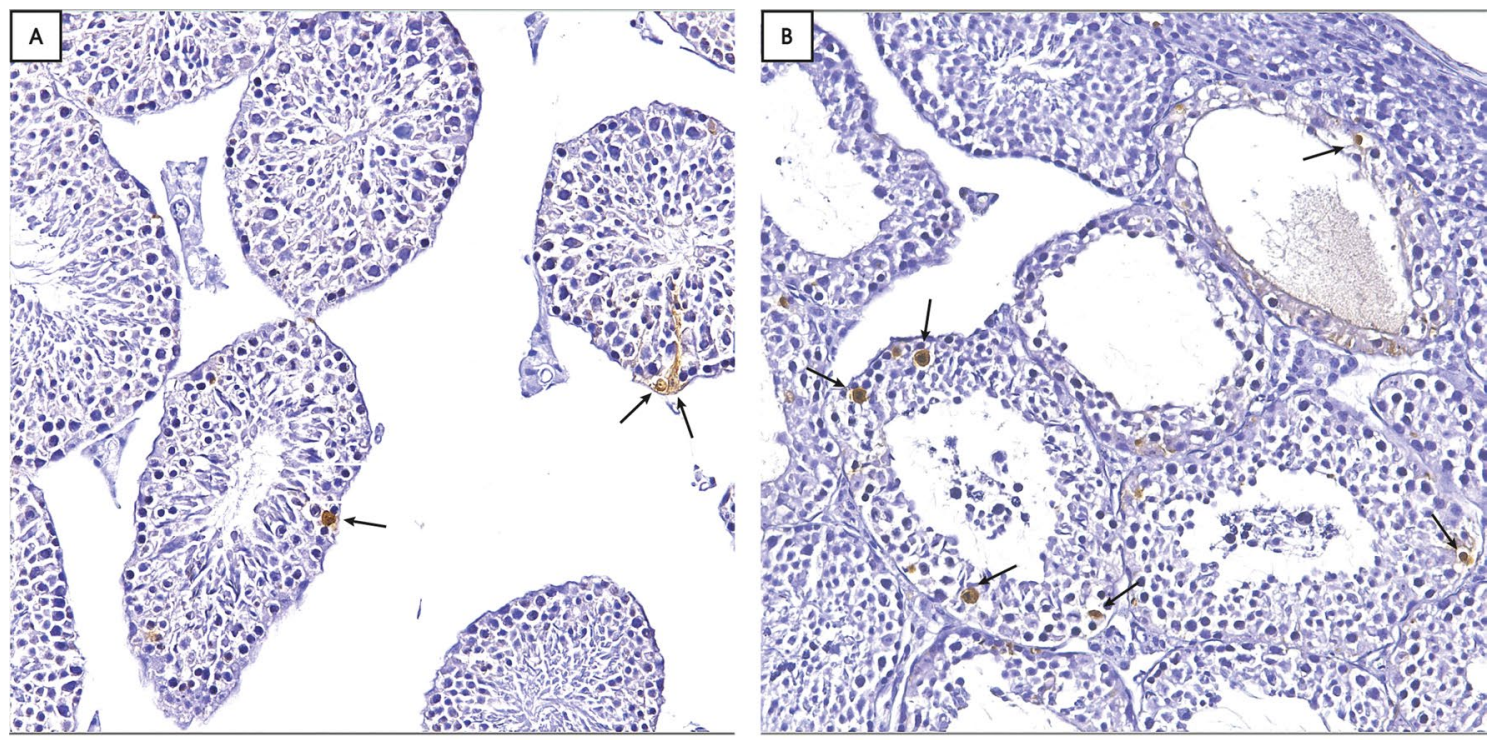

C

TUNEL-positive stained cells
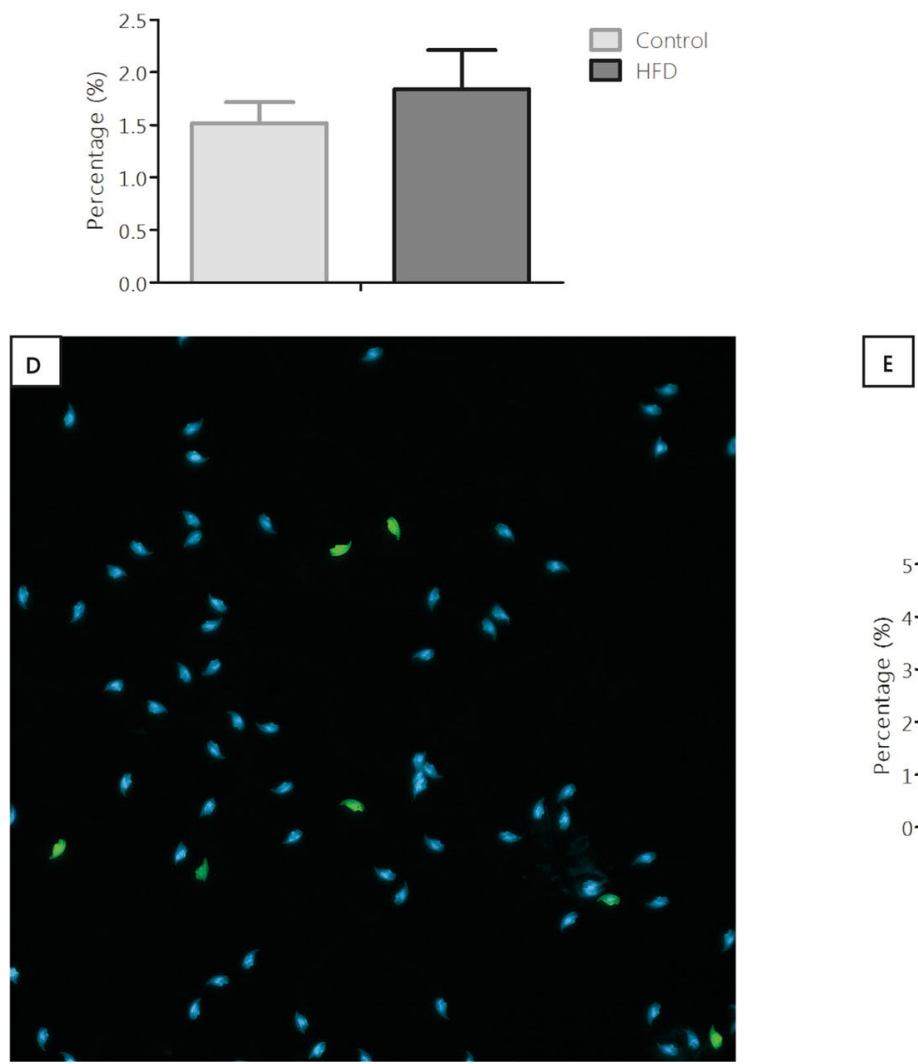

Figure 4. Analysis and representative images of the TUNEL and CMA3 staining. (A) Testis section with few TUNEL-positive cells (indicated with arrows). (B) Testis section with many TUNEL-positive cells. Original magnifications $\times 200$. (C) Analysis of the percentage TUNEL-positive stained cells in the testes. Control $n=13$. HFD $n=14$. (D) Example of an overlay CMA3 staining with the CMA3-positive spermatozoa (green) and the CMA3-negative spermatozoa (DAPI, blue). See supplementary figure S3 for the separate channels of the overlay. (E) Analysis of the percentage CMA3-positive stained cells in the testes. Original magnifications $\times 400$. HFD $\mathrm{n}=9$, Control $\mathrm{n}=7$.

the testes of the HFD fed mice. Additionally, HFD-induced obesity significantly increased the level of aberrant ITO of the seminiferous tubules and significantly lowered the spermatids/spermatocytes ratio. However, the 
number of Sertoli cells, testicular volume and weight were not affected by 24 weeks of HFD feeding, despite the lower spermatids/spermatocytes ratio. Interestingly, the lowered spermatids/spermatocytes ratio could be compensated by a higher expression of Leydig cells. In more detail, Holm et al. found in human testis biopsies that Leydig cell clusters of more than 15 cells in testicles exhibiting altered testicular structure (Sertoli-cell-only syndrome) or with impaired spermatogenesis ${ }^{51}$. Moreover, they found that the presence of Leydig cell clusters was most pronounced in the testes with an increased luteinizing hormone/testosterone ratio, and that a high proportion of testicular tissue with Leydig cells was associated with a decreased spermatogenic capacity ${ }^{51}$. Leydig cells, responsible for the production of testosterone, express leptin receptors and their function and expression level might be affected by hyperleptinemia ${ }^{52}$. Altogether, HFD probably impaired testicular structure by hyperleptinemia, impaired BTB and membrane fluidity and altered functioning of tight junctions, Sertoli cells and Leydig cells. Future research should examine the expression and function of Leydig cells and tight junctions in relation to HFD-feeding.

In agreement with previous studies, we found that HFD-induced obesity did not affect the total number of the Sertoli cells, spermatocytes and spermatids ${ }^{53-55}$. Additionally, our findings confirmed the importance of the nursing function of Sertoli cells for proper development of sperm cells ${ }^{8,47,48,56}$. Thereby, most probably HFDfeeding did not only affect the quantity of sperm produced, but the also the quality of spermatozoa ${ }^{22-24}$. We found that HFD-induced obesity is associated with a prolongation in stage VII and VIII of spermatogenesis. In more detail, during the stage VII and VIII of seminiferous epithelial cycle of spermatogenesis, important events such as spermatogonial differentiation, initiation of meiosis, initiation of spermatid elongation, and release of fully developed elongated spermatids take place ${ }^{45,57}$. During these critical events the cell adhesion proteins have to reorganise in, for example, the preleptotene stage, where spermatocytes have to enter the BTB and to release the elongated spermatozoa to the lumen of the tubule ${ }^{58,59}$. As mentioned before, increased leptin levels can directly affect testicular structure causing aberrant intra-tubular organisation ${ }^{43}$. Furthermore, high leptin levels can affect the HPG-axis and high free testosterone levels might disrupt the nurturing properties of Sertoli cells $^{10,44}$. Moreover, abnormal testosterone levels can affect the regulatory role of Sertoli cells and specifically the production of adhesion molecules and subsequently the release of spermatozoa in the spermatogenic cycle ${ }^{60,61}$. In addition, lipid content and membrane fluidity modulate maturation of spermatozoa ${ }^{62}$. These described processes could affect spermatogenesis and delay spermatogenesis in this critical stage of the spermatogenic cycle. However, regarding the quality of spermatozoa, indicated by DNA-damage or chromatin condensation, we found no significant difference between dietary groups. Future research should focus on biological processes that can particularly affect the spermatids/spermatocytes ratio and above all the critical processes in stage VII and VII of spermatogenesis, for instance hyperleptinemia, abnormal testosterone levels, lipid composition and membrane fluidity affected by HFD-feeding in the testis. Finally, in future studies the exact biological processes for the spermatogenic delay at the critical events, mostly during spermiation in stages VII and VIII should be enlightened, for instance in adhesion proteins and membrane fluidity and lipid content.

Translational rodent models are the cornerstones for biological studies of human disease pathogenesis. Interestingly, the human disease pathogenesis and key biological pathways and metabolomics are not always totally reflected in commonly used rodent models. For instance, C57BL/6 mice need a very long period of $45 \%$ HFD feeding (> 24 weeks) to induce hypercholesteremia and hypertriglyceridemia, which are two key factors in human obesity. Other studies showed that many commonly used rodent models for human pathologies like NAFLD ${ }^{63}$, obesity $^{64}$ or cardiovascular disease ${ }^{65,66}$ did not represent key biological pathways in human pathologies ${ }^{63}$. Therefore, we selected the $\mathrm{Ldlr}^{-1-}$. Leiden mouse model of which we certainly know it reflects key pathways and metabolomics in human obesity ${ }^{67,68}$, like adipose tissue inflammation, hypercholesteremia, hyperlipidemia and insulin resistance $33,34,36,68,69$. Notably, the lack of the Ldlr can increase cholesterol levels compared to C57BL/6j mice ${ }^{35,70}$, which might influence normal spermatogenesis ${ }^{71}$. Moreover, many studies that have investigated obesity in relation to male fertility use an ob/ob mouse model. The ob/ob mouse is leptin deficient, whereas leptin is strongly increased in humans with obesity ${ }^{72}$, thus devoid of a factor which affects normal spermatogenesis ${ }^{17,73-75}$. Therefore, future research should in detail examine the role of the Ldlr and leptin deficiency in normal spermatogenesis, particularly tight junctions, Sertoli cells and Leydig cells.

\section{Conclusion}

This study has demonstrated that 24-weeks of HFD-feeding in the $\mathrm{Ldlr}^{-/-}$. Leiden mice induced impaired testicular structure, which was associated with an altered spermatids/spermatocytes ratio. Furthermore, HFD-feeding could prolong the spermatogenic cycle in stage VII and VII when four critical events in spermatogenesis take place. Our findings substantiate the emerging evidence of the negative impact of obesity on male fertility and stress the importance of lifestyle guidelines in treatment of male infertility.

\section{Materials and methods}

Animals and conditions. Male transgenic $\mathrm{Ldlr}^{-/-}$. Leiden mice originated from SPF breeding stock at TNO Leiden (TNO Metabolic Health Research, Leiden, The Netherlands) were group-housed in digitally ventilated cages (DVC, Tecniplast S.p.A., Buguggiate, Italy) in conventional animal rooms (relative humidity: 50-60\%, temperature: $\pm 21^{\circ} \mathrm{C}$, light cycle 7 a.m. -7 p.m.) at the central animal laboratory, Radboud university medical center, the Netherlands. The mice had an ad libitum access to food and acidified tap water. The $\mathrm{Ldlr}^{-1-}$.Leiden mouse model was chosen because when fed a HFD, adult $\mathrm{Ldlr}^{-/}$. Leiden mice are prone to develop diet-induced obesity, adipose tissue inflammation, hypercholesteremia, hyperlipidemia and insulin resistance ${ }^{33,34,36}$, reflecting key pathways and metabolomics similar to those in human obesity ${ }^{67,68}$.

The experimental approach was approved by an independent institutional ethical committee on animal care and experimentation [Centrale Commissie Dierproeven (CCD), The Hague, The Netherlands], approval number: 
AVD5010020173464, Radboud university project number: 2017-0063-001). All experiments were performed in accordance with relevant guidelines and regulations. Moreover, statistical power analyses were conducted to minimise the number of animals used in this study, and the ARRIVE guidelines of experimental performance and reporting were met $^{76}$.

At weaning ( 3 weeks of age), 30 male $\mathrm{Ldlr}^{-/}$.Leiden pups were divided over cages using block-randomisation, resulting in 3-4 animals per cage. Litters were never in the same cage and equally divided over both dietary groups. All mice were fed a standardised reference diet (Sniff R/M-H diet V1530, Sniff Spezialdiäten GmbH, Soest, Germany) until 12 weeks of age. Then, the mice were randomly divided into two dietary groups (control or HFD/intervention group and 15 mice in each group), the control group (Control, $\mathrm{n}=15$ ) maintained the standardised reference diet (Sniff, Germany) until the end of the study (36 weeks of age). The HFD group received a 45\% lard high fat diet [HFD, D12451, Research diets, New Brunswick, USA (Supplementary data, Table S2)] for 24 weeks (HFD, $n=15$ ), until 36 weeks of age. In this study, individual body weight was measured weekly, and percentage of body fat was indicated by dividing the total fat depots (epididymal, mesenteric and inguinal) weight by body weight at sacrifice.

Plasma analyses. After $5 \mathrm{~h}$ of fasting ( 8 a.m.-1 p.m.), blood was collected by a tail vein incision, after which EDTA plasma was isolated. Plasma analyses were performed using standardized protocols and assays ${ }^{34,77,78}$. In more detail, total plasma levels of cholesterol and triglycerides were determined using enzymatic assays (CHODPAP and GPO-PAP respectively; Roche Diagnostics, Almere, the Netherlands). Total plasma levels for leptin were analysed using standardized protocols and standardized ELISA kits (R\&D Systems, Inc., Minneapolis, MN, USA $)^{34}$. Total testosterone concentrations were measured by LC-MS/MS after solid phase extraction ${ }^{79}$.

Histological analysis of the testis. At the age of 36 weeks, the mice were anaesthetised (3.5\% isoflurane, Nicholas Primal (I) limited, London, UK) and sacrificed by transcardial perfusion with $0.1 \mathrm{M}$ phosphatebuffered saline (PBS, $7.3 \mathrm{pH}$, room temperature). The testes were immediately harvested after euthanasia. The left testis was snap-frozen in liquid nitrogen and preserved at $-80^{\circ} \mathrm{C}$. The right testis was fixed overnight in $4 \%$ paraformaldehyde and preserved in $0.1 \mathrm{M} \mathrm{PBS}$ with $0.01 \%$ sodium azide at $4{ }^{\circ} \mathrm{C}$.

The right testis was weighed $(\mathrm{g})$ and the length, depth and width was measured in $\mathrm{mm}$, and an ellipsoid formula (volume $=0.52 \times$ depth $\times$ length $\times$ width) was used to calculate testis volume ${ }^{80,81}$. Then the testis was embedded in paraffin in vertical position ${ }^{80,81}$. The embedded testis-tissue was sliced with a microtome into $4 \mu \mathrm{m}$ thick sections. In the middle of the testes, four paraffin sections were selected with an interval of approximately $60 \mu \mathrm{m}$, and stained with haematoxylin and eosin (H\&E). These H\&E stained sections were used for morphological analysis of the testicular structure ${ }^{45,82}$. Per mouse four testis sections were analyses using a standardized grid and method to randomly select 13 seminiferous tubules per paraffin section using Stereo Investigator setup of Microbrightfield bioscience (MBF Bioscience, Williston, USA). Subsequently, the relative and absolute number of seminiferous tubules in the testis were measured by using the program Fiji (Fiji (Is Just ImageJ), maintained by Eliceiri/LOCI group, University of Wisconsin-Madison, USA \& the Jug and Tomancak labs, Dresden, Germany). The thickness of seminiferous epithelium was indicated by measuring the width of the epithelium with Fiji (52 epithelia per mouse). Furthermore, the testicular sections were evaluated for the presence of different types of atypical tubules (Supplementary Fig. S1). For all 52 seminiferous tubules per mouse, the number of tubules in which the germ cells were loosely arranged (hereafter referred to as 'aberrant intra-tubular organisation' or AITO), were counted. Testis with a severe level of loosely arranged germ cells [Sertoli-cell-only syndrome (SCO)] were excluded from the analyses $(n=2$ Control group and $n=1$ HFD group, Supplementary Fig. S1).

The number of Sertoli cells, primary spermatocytes and elongating spermatids were counted in the midsection (four sections of $4 \mu \mathrm{m}$ thick, interval of $60 \mu \mathrm{m}$ ) of the testis in 52 seminiferous tubules per mouse per mouse (see Supplementary Fig. S2). All quantifications and the nature of the section were analysed using standardized methods and by a blinded expert. For the analysis of the development of the germ cells, the ratio of elongating spermatids over spermatocytes was manually calculated. In these same tubules the stage of spermatogenic development was determined as well, following Oakberg's description ${ }^{83}$.

TUNEL and CMA3 staining. To evaluate the consequences of the previous described delay in spermatogenic development at the level of sperm chromatin condensation and DNA damage, we performed a terminal deoxynucleotidyl transferase dUTP nick end labelling (TUNEL) assay ${ }^{84}$ to examine DNA damage and fragmentation in testis sections and evaluated chromatin condensation (CMA3+) in epididymal spermatozoa. In four paraffin testis sections per mouse, the TUNEL assay was performed using the DeadEnd Colorimetric TUNEL System from Promega (Promega Corporation, Madison, USA) following the manufacturer's protocol ${ }^{84}$. After staining the sections were rinsed in running tap water for $1 \mathrm{~min}$, dehydrated with $99.5 \%$ ethanol and xylene and mounted with quick-D mounting medium ${ }^{84}$. Labelled (brown coloured) apoptotic cells were manually counted for all 52 seminiferous tubules per mouse using Stereo Investigator setup of Microbrightfield bioscience (MBF Bioscience, Williston, USA) at $20 \times$ magnification.

To examine sperm chromatin condensation, a chemical staining with chromomycin A3 (CMA3) was performed using a standardised protocol ${ }^{85}$, as this compound binds to DNA if not fully compacted. Spermatozoa were collected from the epididymis of the left-side snap-frozen testis. The obtained sperm sample was then diluted with freezing medium and cryopreserved in liquid nitrogen. For the CMA3 staining, the frozen sperm samples were thawed, fixated with methanol and acetic acid on slides, stained, air-dried, and mounted with VECTAshield (Vector Laboratories, Inc. Burlingame, United States).

The proportion of damaged cells (TUNEL assay) or positive for the CMA3 staining was analysed by counting the number of positive stained cells per field, using brightfield and fluorescence microscopy (I3, excitation 
BP 450-490 nm, emission LP515) respectively. For the CMA3 staining, an average of 250 spermatozoa (with a minimum of 200 cells) per proband was counted and the percentage of CMA3-positive cells was calculated. Of detail, two samples showed an extreme high percentage of CMA3 + cells, which we could not explain on a biological ground. We therefore we decided to exclude these samples for the CMA3 + analysis. For the TUNEL quantification, the number of positive cells and the developmental stage of the germ cell was registered. Two testis sections per mice were completely scanned for TUNEL-positive cells and the percentage of TUNEL-positive cells in relation to the number of seminiferous tubules present in the sections was calculated.

Statistical analysis. Throughout the whole study, a random and blocked, double-blind selection procedure was applied. The results are presented as mean \pm standard error of the mean (SEM). The means were analysed using one-way Analysis of Variance (ANOVA) in a statistical program, SPSS25 (IBM SPSS Statistics 25, IBM Corporation, Armonk, New York, USA). Correlation tests were performed with Pearson's correlations. Due to skewed distribution, the testes weight and percentage loosely arranged tubules were log transformed. No equal variances were assumed for the plasma testosterone levels and were therefore statistically analysed in the nonparametric Mann-Whitney $U$ test and correlated using the Spearman rho's test. The results were referred to as significant if the P-value was 0.05 or lower ( $\mathrm{p}$ - and F-values are both presented in the results).

Received: 15 June 2021; Accepted: 10 December 2021

Published online: 11 January 2022

\section{References}

1. Gesink Law, D. C., Maclehose, R. F. \& Longnecker, M. P. Obesity and time to pregnancy. Hum. Reprod. 22, 414-420. https://doi. org/10.1093/humrep/del400 (2007).

2. Pasquali, R., Pelusi, C., Genghini, S., Cacciari, M. \& Gambineri, A. Obesity and reproductive disorders in women. Hum. Reprod. Update 9, 359-372 (2003).

3. Zain, M. M. \& Norman, R. J. Impact of obesity on female fertility and fertility treatment. Womens Health 4, 183-194. https://doi. org/10.2217/17455057.4.2.183 (2008).

4. Bieniek, J. M. et al. Influence of increasing body mass index on semen and reproductive hormonal parameters in a multi-institutional cohort of subfertile men. Fertil. Steril. 106, 1070-1075. https://doi.org/10.1016/j.fertnstert.2016.06.041 (2016).

5. Craig, J. R., Jenkins, T. G., Carrell, D. T. \& Hotaling, J. M. Obesity, male infertility, and the sperm epigenome. Fertil. Steril. 107, 848-859. https://doi.org/10.1016/j.fertnstert.2017.02.115 (2017).

6. Palmer, N. O., Bakos, H. W., Fullston, T. \& Lane, M. Impact of obesity on male fertility, sperm function and molecular composition. Spermatogenesis 2, 253-263. https://doi.org/10.4161/spmg.21362 (2012).

7. Hammoud, A. O., Gibson, M., Peterson, C. M., Meikle, A. W. \& Carrell, D. T. Impact of male obesity on infertility: A critical review of the current literature. Fertil. Steril. 90, 897-904. https://doi.org/10.1016/j.fertnstert.2008.08.026 (2008).

8. Davidson, L. M., Millar, K., Jones, C., Fatum, M. \& Coward, K. Deleterious effects of obesity upon the hormonal and molecular mechanisms controlling spermatogenesis and male fertility. Hum. Fertil. 18, 184-193. https://doi.org/10.3109/14647273.2015. 1070438 (2015).

9. Rao, P. M., Kelly, D. M. \& Jones, T. H. Testosterone and insulin resistance in the metabolic syndrome and T2DM in men. Nat. Rev. Endocrinol. 9, 479-493. https://doi.org/10.1038/nrendo.2013.122 (2013).

10. Wang, X., Zhang, X., Hu, L. \& Li, H. Exogenous leptin affects sperm parameters and impairs blood testis barrier integrity in adult male mice. Reprod. Biol. Endocrinol. 16, 55-55. https://doi.org/10.1186/s12958-018-0368-4 (2018).

11. Akingbemi, B. T. Estrogen regulation of testicular function. Reprod. Biol. Endocrinol. 3, 51. https://doi.org/10.1186/1477-7827-3-51 (2005).

12. Pasquali, R. Obesity and androgens: Facts and perspectives. Fertil. Steril. 85, 1319-1340. https://doi.org/10.1016/j.fertnstert.2005. 10.054 (2006).

13. Pasquali, R., Patton, L. \& Gambineri, A. Obesity and infertility. Curr. Opin. Endocrinol. Diabetes Obes. 14, 482-487. https://doi. org/10.1097/MED.0b013e3282f1d6cb (2007).

14. Thomsen, L., Humaidan, P., Bungum, L. \& Bungum, M. The impact of male overweight on semen quality and outcome of assisted reproduction. Asian J. Androl. 16, 749-754. https://doi.org/10.4103/1008-682x.125398 (2014).

15. Vernet, P., Fulton, N., Wallace, C. \& Aitken, R. J. Analysis of reactive oxygen species generating systems in rat epididymal spermatozoa. Biol. Reprod. 65, 1102-1113 (2001).

16. Liu, Y. \& Ding, Z. Obesity, a serious etiologic factor for male subfertility in modern society. Reproduction 154, R123-r131. https:// doi.org/10.1530/rep-17-0161 (2017).

17. Duale, N. et al. Impaired sperm chromatin integrity in obese mice. Andrology 2, 234-243. https://doi.org/10.1111/j.2047-2927. 2013.00178.x (2014).

18. Fariello, R. M. et al. Association between obesity and alteration of sperm DNA integrity and mitochondrial activity. BJU Int. 110, 863-867. https://doi.org/10.1111/j.1464-410X.2011.10813.x (2012).

19. Mortazavi, M., Salehi, I., Alizadeh, Z., Vahabian, M. \& Roushandeh, A. M. Protective effects of antioxidants on sperm parameters and seminiferous tubules epithelium in high fat-fed rats. J. Reprod. Infertil. 15, 22-28 (2014).

20. Sakkas, D. \& Alvarez, J. G. Sperm DNA fragmentation: Mechanisms of origin, impact on reproductive outcome, and analysis. Fertil. Steril. 93, 1027-1036. https://doi.org/10.1016/j.fertnstert.2009.10.046 (2010).

21. Vernet, P., Aitken, R. J. \& Drevet, J. R. Antioxidant strategies in the epididymis. Mol. Cell. Endocrinol. 216, 31-39. https://doi.org/ 10.1016/j.mce.2003.10.069 (2004).

22. Dupont, C. et al. Obesity leads to higher risk of sperm DNA damage in infertile patients. Asian J. Androl. 15, 622-625. https://doi. org/10.1038/aja.2013.65 (2013)

23. Kort, H. I. et al. Impact of body mass index values on sperm quantity and quality. J. Androl. 27, 450-452. https://doi.org/10.2164/ jandrol.05124 (2006).

24. La Vignera, S., Condorelli, R. A., Vicari, E. \& Calogero, A. E. Negative effect of increased body weight on sperm conventional and nonconventional flow cytometric sperm parameters. J. Androl. 33, 53-58. https://doi.org/10.2164/jandrol.110.012120 (2012).

25. Bakos, H. W., Henshaw, R. C., Mitchell, M. \& Lane, M. Paternal body mass index is associated with decreased blastocyst development and reduced live birth rates following assisted reproductive technology. Fertil. Steril. 95, 1700-1704. https://doi.org/10.1016/j. fertnstert.2010.11.044 (2011). 
26. Jensen, T. K. et al. Body mass index in relation to semen quality and reproductive hormones among 1,558 Danish men. Fertil. Steril. 82, 863-870. https://doi.org/10.1016/j.fertnstert.2004.03.056 (2004).

27. Zhang, J. et al. The negative impact of higher body mass index on sperm quality and erectile function: A cross-sectional study among Chinese males of infertile couples. Am. J. Mens Health 13, 1557988318822572. https://doi.org/10.1177/1557988318822572 (2019).

28. Wu, F. C. et al. Hypothalamic-pituitary-testicular axis disruptions in older men are differentially linked to age and modifiable risk factors: The European Male Aging Study. J. Clin. Endocrinol. Metab. 93, 2737-2745. https://doi.org/10.1210/jc.2007-1972 (2008).

29. Aggerholm, A. S., Thulstrup, A. M., Toft, G., Ramlau-Hansen, C. H. \& Bonde, J. P. Is overweight a risk factor for reduced semen quality and altered serum sex hormone profile?. Fertil. Steril. 90, 619-626. https://doi.org/10.1016/j.fertnstert.2007.07.1292 (2008).

30. Chavarro, J. E., Toth, T. L., Wright, D. L., Meeker, J. D. \& Hauser, R. Body mass index in relation to semen quality, sperm DNA integrity, and serum reproductive hormone levels among men attending an infertility clinic. Fertil. Steril. 93, 2222-2231. https:// doi.org/10.1016/j.fertnstert.2009.01.100 (2010).

31. Pauli, E. M. et al. Diminished paternity and gonadal function with increasing obesity in men. Fertil. Steril. 90, 346-351. https:// doi.org/10.1016/j.fertnstert.2007.06.046 (2008).

32. Rybar, R., Kopecka, V., Prinosilova, P., Markova, P. \& Rubes, J. Male obesity and age in relationship to semen parameters and sperm chromatin integrity. Andrologia 43, 286-291. https://doi.org/10.1111/j.1439-0272.2010.01057.x (2011).

33. Morrison, M. C., Kleemann, R., van Koppen, A., Hanemaaijer, R. \& Verschuren, L. J. F. Key inflammatory processes in human NASH are reflected in Ldlr-/- Leiden mice: A translational gene profiling study. Andrologia 9, 132 (2018).

34. Morrison, M. C. et al. Obeticholic acid modulates serum metabolites and gene signatures characteristic of human NASH and attenuates inflammation and fibrosis progression in $\mathrm{Ldlr}^{-/}$. Leiden mice. Hepatol. Commun. 2, 1513-1532. https://doi.org/10.1002/ hep4.1270 (2018).

35. Arnoldussen, I. A. C. et al. Milk fat globule membrane attenuates high fat diet-induced neuropathological changes in obese $\mathrm{Ldlr}^{-/-}$. Leiden mice. Int. J. Obes. https://doi.org/10.1038/s41366-021-00998-w (2021).

36. Arnoldussen, I. A. C. et al. Butyrate restores HFD-induced adaptations in brain function and metabolism in mid-adult obese mice. Int. J. Obes. 41, 935-944. https://doi.org/10.1038/ijo.2017.52 (2017).

37. Tengeler, A. C. et al. Propionic acid and not caproic acid, attenuates nonalcoholic steatohepatitis and improves (cerebro) vascular functions in obese Ldlr $\left(^{(-)}\right)$.Leiden mice. FASEB J https://doi.org/10.1096/ff.202000455R (2020).

38. Fui, M. N. T., Dupuis, P. \& Grossmann, M. Lowered testosterone in male obesity: mechanisms, morbidity and management. Asian J. Androl. 16, 223-231. https://doi.org/10.4103/1008-682X.122365 (2014).

39. Giovambattista, A. et al. Modulatory effects of leptin on leydig cell function of normal and hyperleptinemic rats. Neuroendocrinology 78, 270-279. https://doi.org/10.1159/000074448 (2003).

40. Caesar, R. et al. A combined transcriptomics and lipidomics analysis of subcutaneous, epididymal and mesenteric adipose tissue reveals marked functional differences. PLoS ONE 5, e11525 (2010).

41. de Catalfo, G. E. H., de Alaniz, M. \& Marra, C. A. J. L. Influence of commercial dietary oils on lipid composition and testosterone production in interstitial cells isolated from rat testis. Lipids 44, 345-357 (2009).

42. Gromadzka-Ostrowska, J. J. R. B. Effects of dietary fat on androgen secretion and metabolism. Lipids 6, 13-20 (2006).

43. Yuan, M. et al. Hyperleptinemia directly affects testicular maturation at different sexual stages in mice, and suppressor of cytokine signaling 3 is involved in this process. Reprod. Biol. Endocrinol. 12, 15. https://doi.org/10.1186/1477-7827-12-15 (2014).

44. Martins, A. D. et al. Leptin modulates human Sertoli cells acetate production and glycolytic profile: A novel mechanism of obesityinduced male infertility?. Reprod. Biol. Endocrinol. 1852, 1824-1832 (2015).

45. Fan, Y. et al. Diet-induced obesity in male C57BL/6 mice decreases fertility as a consequence of disrupted blood-testis barrier. PLoS ONE 10, e0120775-e0120775. https://doi.org/10.1371/journal.pone.0120775 (2015).

46. Skinner, M. K. \& Griswold, M. D. Sertoli Cell Biology (Elsevier, 2004).

47. Iliadou, P. K., Tsametis, C., Kaprara, A., Papadimas, I. \& Goulis, D. G. The Sertoli cell: Novel clinical potentiality. Hormones 14, 504-514. https://doi.org/10.14310/horm.2002.1648 (2015).

48. Holstein, A.-F., Schulze, W. \& Davidoff, M. Understanding spermatogenesis is a prerequisite for treatment. Reprod. Biol. Endocrinol. 1, 107-107. https://doi.org/10.1186/1477-7827-1-107 (2003).

49. Cazzola, R., Rondanelli, M., Russo-Volpe, S., Ferrari, E. \& Cestaro, B. Decreased membrane fluidity and altered susceptibility to peroxidation and lipid composition in overweight and obese female erythrocytes. J. Lipid Res. 45, 1846-1851 (2004).

50. Kahle, M. et al. High fat diet-induced modifications in membrane lipid and mitochondrial-membrane protein signatures precede the development of hepatic insulin resistance in mice. Mol. Metab. 4, 39-50. https://doi.org/10.1016/j.molmet.2014.11.004 (2015).

51. Holm, M., Rajpert-De Meyts, E., Andersson, A. M. \& Skakkebæk, N. E. Leydig cell micronodules are a common finding in testicular biopsies from men with impaired spermatogenesis and are associated with decreased testosterone/LH ratio. J. Pathol. 199, 378-386 (2003).

52. Ishikawa, T., Fujioka, H., Ishimura, T., Takenaka, A. \& Fujisawa, M. Expression of leptin and leptin receptor in the testis of fertile and infertile patients. Andrologia 39, 22-27. https://doi.org/10.1111/j.1439-0272.2006.00754.x (2007).

53. Steinfeld, K. et al. Low testosterone in ApoE/LDL receptor double-knockout mice is associated with rarefied testicular capillaries together with fewer and smaller Leydig cells. Sci. Rep. 8, 5424. https://doi.org/10.1038/s41598-018-23631-9 (2018).

54. Bakos, H. W., Mitchell, M., Setchell, B. P. \& Lane, M. The effect of paternal diet-induced obesity on sperm function and fertilization in a mouse model. Int. J. Androl. 34, 402-410. https://doi.org/10.1111/j.1365-2605.2010.01092.x (2011).

55. Ghanayem, B. I., Bai, R., Kissling, G. E., Travlos, G. \& Hoffler, U. Diet-induced obesity in male mice is associated with reduced fertility and potentiation of acrylamide-induced reproductive toxicity. Biol. Reprod. 82, 96-104. https://doi.org/10.1095/biolreprod. 109.078915 (2010).

56. Ross, M. H. \& Pawlina, W. Histology (Lippincott Williams \& Wilkins, 2006).

57. Endo, T., Freinkman, E., de Rooij, D. G. \& Page, D. C. Periodic production of retinoic acid by meiotic and somatic cells coordinates four transitions in mouse spermatogenesis. Proc. Natl. Acad. Sci. 114, E10132-E10141. https://doi.org/10.1073/pnas.1710837114 (2017).

58. Cheng, C. Y. \& Mruk, D. D. A local autocrine axis in the testes that regulates spermatogenesis. Nat. Rev. Endocrinol. 6, 380-395. https://doi.org/10.1038/nrendo.2010.71 (2010).

59. Mruk, D. D. \& Cheng, C. Y. Sertoli-Sertoli and Sertoli-germ cell interactions and their significance in germ cell movement in the seminiferous epithelium during spermatogenesis. Endocr. Rev. 25, 747-806. https://doi.org/10.1210/er.2003-0022 (2004).

60. Smith, L. B. \& Walker, W. H. The regulation of spermatogenesis by androgens. Semin. Cell Dev. Biol. 30, 2-13. https://doi.org/10. 1016/j.semcdb.2014.02.012 (2014).

61. Stanton, P. G. et al. Proteomic changes in rat spermatogenesis in response to in vivo androgen manipulation; impact on meiotic cells. PLoS ONE 7, e41718-e41718. https://doi.org/10.1371/journal.pone.0041718 (2012).

62. Force, A. et al. Membrane fluidity and lipid content of human spermatozoa selected by swim-up method. Int. J. Androl. 24, 327-334. https://doi.org/10.1046/j.1365-2605.2001.00309.x (2001).

63. Teufel, A. et al. Comparison of gene expression patterns between mouse models of nonalcoholic fatty liver disease and liver tissues from patients. Gastroenterology 151, 513-525.e510. https://doi.org/10.1053/j.gastro.2016.05.051 (2016).

64. Jacobs, S. A. et al. Sex-specific differences in fat storage, development of non-alcoholic fatty liver disease and brain structure in juvenile HFD-induced obese $\mathrm{ldlr}^{-1-}$.leiden mice. Nutrients 11, 1861 (2019). 
65. van De Poll, S. W. et al. Raman spectroscopic evaluation of the effects of diet and lipid-lowering therapy on atherosclerotic plaque development in mice. Arterioscler. Thromb. Vasc. Biol. 21, 1630-1635 (2001).

66. Zadelaar, S. et al. Mouse models for atherosclerosis and pharmaceutical modifiers. Arterioscler. Thromb. Vasc. Biol. 27, $1706-1721$. https://doi.org/10.1161/atvbaha.107.142570 (2007).

67. van den Hoek, A. M. et al. Diet and exercise reduce pre-existing NASH and fibrosis and have additional beneficial effects on the vasculature, adipose tissue and skeletal muscle via organ-crosstalk. Metabolism 124, 154873. https://doi.org/10.1016/j.metabol. $2021.154873(2021)$.

68. van den Hoek, A. M. et al. A translational mouse model for NASH with advanced fibrosis and atherosclerosis expressing key pathways of human pathology. Cells $\mathbf{9}, 2014$ (2020).

69. van Koppen, A. et al. Uncovering a predictive molecular signature for the onset of NASH-related fibrosis in a translational NASH mouse model. Cell Mol. Gastroenterol. Hepatol. 5, 83-98.e10. https://doi.org/10.1016/j.jcmgh.2017.10.001 (2018).

70. van der Heijden, R. A. et al. Obesity-induced chronic inflammation in high fat diet challenged C57BL/6J mice is associated with acceleration of age-dependent renal amyloidosis. Sci. Rep. 5, 16474. https://doi.org/10.1038/srep16474 (2015).

71. Sèdes, L. et al. Cholesterol: A gatekeeper of male fertility?. Front. Endocrinol. https://doi.org/10.3389/fendo.2018.00369 (2018).

72. Zhao, S. et al. Partial leptin reduction as an insulin sensitization and weight loss strategy. Cell Metab. 30, 706-719.e706. https:// doi.org/10.1016/j.cmet.2019.08.005 (2019).

73. Bhat, G. K. et al. Influence of a leptin deficiency on testicular morphology, germ cell apoptosis, and expression levels of apoptosisrelated genes in the mouse. J. Androl. 27, 302-310. https://doi.org/10.2164/jandrol.05133 (2006).

74. Hoffmann, A. et al. Leptin within the subphysiological to physiological range dose dependently improves male reproductive function in an obesity mouse model. Endocrinology 157, 2461-2468. https://doi.org/10.1210/en.2015-1966 (2016).

75. Pelletier, R. M., Akpovi, C. D., Chen, L. \& Vitale, M. L. Cholesterol metabolism and Cx43, Cx46, and Cx50 gap junction protein expression and localization in normal and diabetic and obese ob/ob and $\mathrm{db} / \mathrm{db}$ mouse testes. Am. J. Physiol. Endocrinol. Metab. 314, E21-e38. https://doi.org/10.1152/ajpendo.00215.2017 (2018).

76. Kilkenny, C., Browne, W. J., Cuthill, I. C., Emerson, M. \& Altman, D. G. Improving bioscience research reporting: The ARRIVE guidelines for reporting animal research. PLoS Biol. 8, e1000412. https://doi.org/10.1371/journal.pbio.1000412 (2010).

77. Wielinga, P. Y. et al. Arachidonic acid/docosahexaenoic acid-supplemented diet in early life reduces body weight gain, plasma lipids, and adiposity in later life in ApoE*3Leiden mice. Mol. Nutr. Food Res. 56, 1081-1089. https://doi.org/10.1002/mnfr.20110 $0762(2012)$.

78. Schoemaker, M. H. et al. A casein hydrolysate based formulation attenuates obesity and associated non-alcoholic fatty liver disease and atherosclerosis in $\mathrm{LDLr}^{-1-}$.Leiden mice. PLoS ONE 12, e0180648. https://doi.org/10.1371/journal.pone.0180648 (2017).

79. ter Horst, R. et al. Host and environmental factors influencing individual human cytokine responses. Anat. Sci. Int. 167, 1111-1124 (2016).

80. Nakata, H. Morphology of mouse seminiferous tubules. Anat. Sci. Int. 94, 1-10. https://doi.org/10.1007/s12565-018-0455-9 (2019).

81. Nakata, H. et al. Three-dimensional structure of seminiferous tubules in the adult mouse. J. Anat. 227, 686-694. https://doi.org/ 10.1111/joa.12375 (2015).

82. Ye, H. \& Ulbright, T. M. Difficult differential diagnoses in testicular pathology. Arch. Pathol. Lab. Med. 136, 435-446. https://doi. org/10.5858/arpa.2011-0475-RA (2012).

83. Oakberg, E. F. Duration of spermatogenesis in the mouse and timing of stages of the cycle of the seminiferous epithelium. Am. J. Anat. 99, 507-516. https://doi.org/10.1002/aja.1000990307 (1956).

84. Promega Corporation, M., USA. (DeadEnd Colorimetric TUNEL System Protocol, 2021).

85. Ramos, L., de Boer, P., Meuleman, E. J. H., Braat, D. D. M. \& Wetzels, A. M. M. Chromatin condensation and DNA damage of human epididymal spermatozoa in obstructive azoospermia. Reprod. Biomed. Online 8, 392-397. https://doi.org/10.1016/S14726483(10)60922-4 (2004).

\section{Acknowledgements}

We would like to thank Vivienne Verweij and Jos Dederen for their excellent biotechnical support and assistance. M.M. and R.K. received support from an internal research program of the Netherlands Organization of Scientific Research 'ERP-BBI 030' and 'PMC-13/15' to characterize physiological processes in the $\mathrm{Ldlr}^{-/-}$.Leiden mouse model.

\section{Author contributions}

Study design: R.K., L.R., A.K. \& I.A. Data analyses: D.K., G.H., M.M., A.H. and I.A. Prepared full manuscript: D.K., G.H., M.M., R.K., L.R., A.K. and I.A. All authors reviewed the manuscript.

\section{Funding}

This research was funded by the Europees Fonds voor Regionale Ontwikkeling (EFRO), Project BriteN 2016.

\section{Competing interests}

The authors declare no competing interests.

\section{Additional information}

Supplementary Information The online version contains supplementary material available at https://doi.org/ 10.1038/s41598-021-04069-y.

Correspondence and requests for materials should be addressed to A.J.K.

Reprints and permissions information is available at www.nature.com/reprints.

Publisher's note Springer Nature remains neutral with regard to jurisdictional claims in published maps and institutional affiliations. 
(c) (i) Open Access This article is licensed under a Creative Commons Attribution 4.0 International cc) License, which permits use, sharing, adaptation, distribution and reproduction in any medium or format, as long as you give appropriate credit to the original author(s) and the source, provide a link to the Creative Commons licence, and indicate if changes were made. The images or other third party material in this article are included in the article's Creative Commons licence, unless indicated otherwise in a credit line to the material. If material is not included in the article's Creative Commons licence and your intended use is not permitted by statutory regulation or exceeds the permitted use, you will need to obtain permission directly from the copyright holder. To view a copy of this licence, visit http://creativecommons.org/licenses/by/4.0/.

(C) The Author(s) 2022 